\title{
Theories of Career Development: Educational and Counseling Implications
}

\author{
Preeti Sharma ${ }^{1 *}$
}

\section{ABSTRACT}

Career Development is a continuous lifelong process of developmental experiences that focuses on seeking, obtaining and processing information about self, occupational and educational alternatives, life styles and role options. Put another way, career development is the process through which people come to understand them as they relate to the world of work and their role in it. This career development process is where an individual fashions a work identity. In educational development, career development provides a person, often a student, and focus for selecting a career or subject to undertake in the future. Educational institutions provide career counsellors to assist students with their educational development.

It is imperative when educating the young people that the current school systems assist and consider the significance of this responsibility for the youth and their future. The influences on and outcomes of career development are one aspect of socialization as part of a broader process of human development. Theories and research describing career behavior provide the "conceptual glue" for as well as describe where, when and for what purpose career counseling, career education, career guidance and other career interventions should be implemented. In educational development, career development provides a person, often a student, and focus for selecting a career or subject to undertake in the future. Educational institutions provide career counsellors to assist students with their educational development. The current paper will focus on the various theories related to career development and their educational implications.

\section{Keywords: Career, Career Development, Theories Of Career, Counseling}

In this age of increasing awareness and globalization, it is extremely essential to sensitize the school and college going students about various career choices available to them. It is important to understand the nature and concept of career before understanding the theories of career development. A career can be defined as "a pattern of work experiences comprising the entire

\footnotetext{
${ }^{1}$ Counselor, Academy of Well-being, Udaipur \& Research Scholar, Pacific University, Udaipur, India *Responding Author

(C) 2016, P Sharma; licensee IJIP. This is an Open Access Research distributed under the terms of the Creative Commons Attribution License (http://creativecommons.org/licenses/by/2.0), which permits unrestricted use, distribution, and reproduction in any Medium, provided the original work is properly cited.
} 


\section{Theories of Career Development: Educational and Counseling Implications}

life span of a person and which is generally seen with regard to a number of phases or stages reflecting the transition from one stage of life to the next” (Weinert, 2001). Super (1957) defines career as "The sequence of major positions occupied by a person throughout his preoccupational, occupational and post occupational life; includes work related roles such as those of student, employee, and pensioner, together with complementary vocational, familial and civil roles". Arthur, Hall and Lawrence (1989), defines career as "the evolving sequence of a person's work experiences over time”. Collin (1998) posits that the orientation towards a particular career arises from the interaction between person and various organizations and the society. It means that the career is a function of both one's internal orientation and external factors. Savickas (2009) states that current view of careers is temporary, contingent, casual, contract, freelance, part-time, external, atypical, self-employed and external. Two of the commonalities emerging from these terms are, firstly that the responsibility to manage a career now falls on the individual. Secondly, all these terms describe a climate of constant change. The term "career" is the sequence of interaction of individuals with society, education and organizations throughout their lifespan. It is necessary, however, to emphasize that the majority of the responsibility now rests on the individual for their own career progression, which requires sustained employability.

From the time of Parsons (1909), the terms career, vocation, and occupation have often been used synonymously. The term career has been criticized for its western middle class focus and the lack of its applicability across cultures and less developed countries .More recently the term 'work' has been applied to this area of human behavior to provide a more inclusive and less conceptually and culturally complex term. The words which have common understanding in career psychology include 'work' which typically refers to the domain of life in which people, paid or unpaid, provide labor for an outcome of a service or a good. 'Job' refers to a specific work position which may be permanent full-time or part-time and in a particular role or organization. 'Career' refers to the sequence of or collection of jobs held over an individual's life, although in western societies it has traditionally been conceptualized as a linear sequence of "jobs" which have a vertical 'advancement related' trajectory. Career psychology is concerned with the interplay between individuals and environments and attempts to describe the nature of the patterns of positions held and resultant experiences during an individual's lifespan. This sub discipline focuses on providing models and explanations for organizational career-related activities such as: the origin and measurement of individual aptitudes, personality, interests and career orientations, motives and values, how individual, social, chance and environmental factors shape educational and training experiences, employee employability, career embeddedness and mobility, experiences of career well-being, job and career satisfaction, career agency, early work history, occupational choice, organizational/job choice and career movements after organizational entry, work/family issues, career plateaus and retirement planning. Career development is a lifelong process of developing beliefs, values, attitudes, skills, personality and knowledge of the world of work. To have interface between education and career development, there are three assumptions common to many career development theories. First, career 


\section{Theories of Career Development: Educational and Counseling Implications}

development is an integral part of one's developmental experiences, second assumption is that career planning and life planning are interrelated process and third assumption is that educational experiences at the primary and secondary school levels play a critical role in the career development process.

Career guidance and counseling in the western world has developed a comprehensive system of theories and intervention strategies in its more than 100 years of history. In an age of economic globalization, all individuals are affected by an array of work related concerns, some of these concerns are unique to certain cultures, but others are common to many cultural groups. The search for life purposes and meanings, the journey to actualize oneself through various life and work- related roles, and the efforts by nations to deal with problems of employment and unemployment, are examples of universal issues that seem to affect many individuals from diverse cultures. Under the theme of career development, there are experiences, concerns, and issues that we could share, explore, and discussed at a global stage. Vocational and career related issues are salient across different cultures and nationalities. The development of career guidance and development into a global discipline requires a set of theoretical frameworks with universal validity and applications, as well as culture-specific models that could be used to explain career development issues and phenomenon at a local level. Some of the important divisions of development theories are as follows.

1. Content Theories: Content refers to the influences on career development which are either intrinsic to the individual themselves or emanate from within the context in which the individual lives. In general, individual influences have been afforded more attention in career theory than contextual influences. Major theories focusing on the 'content' of career development include the psychological approaches of trait and factor theory (Holland, 1973; Parsons, 1909) and Bordin’s (1990) psychodynamic theory.

2. Process Theories: Process refers to interaction and changes over time and is depicted in some theories as a series of stages through which individuals pass. The stage or developmental theories of Ginzberg and his colleagues (1951), and Super (1953) fall in this category.

3. Content and Process Theories: More recently the need for theory to take into account both content (characteristics of the individual and the context), and process (their development and the interaction between them), has been recognized. Theoretical models based on the social learning theory, conceptualized as the social cognitive theory of Bandura (1986), include the learning theory of Mitchell and Krumboltz $(1990,1996)$.

1. Holland's Theory: John Holland's theory (1959) is grounded on a modal of personal orientation or a developmental process established through heredity and the individual's life history of reacting to environmental demands. More simply put, individuals are attracted to a 


\section{Theories of Career Development: Educational and Counseling Implications}

particular occupation that meets their personal needs and provides them satisfaction.Holland's theory is based on four assumptions:

- Persons can be categorized as one of the following: Realistic(R-Physical activities, things), Investigative(R-thinking, problem solving, scientific activities), Artistic (A-free, unstructured, creative pursuits.), Social (S-teaching, helping roles.), Enterprising (E-persuade, manage people to attain goals.) or Conventional (C-orderly, systematic conditions that are directed by others in authority.)

- There are six modal environments: realistic, investigative, artistic, social, enterprising and conventional.

- People search for environments that will let them exercise their skills and abilities, express their attitudes and values, and take on agreeable problems and roles.

- Behavior is determined by an interaction between personality and environment.

Holland argues that personality is permanent, and he asserts that early life experience, selfperceptions and values influence the development of behaviors or personality. But his personality theory stresses that individuals are drawn to certain careers as a result of their personalities Holland argues that career is an extension and expression of one's personality within the context of the world of work, and a subsequent identification with specific occupational stereotypes. Where individuals compare themselves to their own perceptions of occupations and either accept or reject them based on the psychological and sociological relevance an occupation holds for them. If a person's degree of resemblance to the six vocational personality and interest types could be assessed, then it is possible to generate a three-letter code (e.g., SIA, RIA) to denote and summarise one's career interest. The first letter of the code is a person's primary interest type, which would likely play a major role in career choice and satisfaction. The second and third letters are secondary interest themes, and they would likely play a lesser but still significant role in the career choice process. Holland postulated that vocational environments could be arranged into similar typologies. In the career choice and development process, people search for environments that would allow them to exercise their skills and abilities, and to express their attitudes and values. In any given vocational environment, there is a tendency to shape its composition so that its characteristics are like the dominant persons in there, and those who are dissimilar to the dominant types are likely to feel unfulfilled and dis- satisfied. The concept of "congruence" is used by Holland to denote the status of person-environment interaction. A high degree of match between a person's personality and interest types and the dominant work environmental types (that is, high degree of congruence) is likely to result in vocational satisfaction and stability, and a low degree of match (that is, low congruence) is likely to result in vocational dissatisfaction and instability. The concept of consistency is used as "a measure of the internal harmony or coherence of an individual's type scores". In addition to congruence and consistency, another major concept in Holland's theory is differentiation. Differentiation refers to whether high interest and low interest types are clearly distinguishable in a person's interest profile. An interest profile that is low in 


\section{Theories of Career Development: Educational and Counseling Implications}

differentiation resembles a relatively flat line in which high and low interest types are not distinctive. In contrast, a differentiated interest profile has clearly high and low scores, suggesting that the crystallization of interest might have occurred, and readiness for career choice specification and implementation.

2. Super's Theory: Super (1969) suggested that career choice and development is essentially a process of developing and implementing a person's self-concept. According to Super, selfconcept is a product of complex interactions among a number of factors, including physical and mental growth, personal experiences, and environmental characteristics and stimulation. Super's theory has called for a stronger emphasis on the effects of social context and the reciprocal influence between the person and the environment. A relatively stable self-concept should emerge in late adolescence to serve as a guide to career choice and adjustment. However, selfconcept is not a static entity and it would continue to evolve as the person encounters new experience and progresses through the developmental stages. Life and work satisfaction is a continual process of implementing the evolving self-concept through work and other life roles. Super (1990) proposed a life stage developmental framework with the following stages: growth, exploration, establishment, maintenance (or management), and disengagement. In each stage one has to successfully manage the vocational developmental tasks that are socially expected of persons in the given chronological age range. For example, in the stage of exploration (ages around 15 to 24), an adolescent has to cope with the vocational developmental tasks of crystallization (a cognitive process involving an understanding of one's interests, skills, and values, and to pursue career goals consistent with that understanding), specification (making tentative and specific career choices), and implementation (taking steps to actualize career choices through engaging in training and job positions). Super (1990) postulated that a mini-

cycle consisting of the same stages from growth to disengagement would likely take place within each of the stages, particularly when a person makes transition from one stage to the next. In addition, individuals would go through a mini-cycle of the stages whenever they have to make expected and unexpected career transitions such as loss of employment or due to personal or socioeconomic circumstances. Donald Super has generated a life span vocational choice theory that has six life and career development stages. These six stages are:

1. The crystallization stage, ages $14-18$

2. Specification stage, ages $18-21$

3. Implementation stage, ages $21-24$

4. The stabilization stage, ages 24-35

5. Consolidation, age 35

6. Readiness for retirement, age 55

In addition to career maturity, there are other aspects of Super's theory that need to be examined across cultures. For example, self-concept is a prominent feature of Super's theory, and the implementation of one's interests, values, and skills in a work role is instrumental to vocational 


\section{Theories of Career Development: Educational and Counseling Implications}

development and satisfaction. However, there are cultural variations in the importance of self in decision-making, and in some cultures important life decisions such as career choices are also subjected to considerations that are familial and collective in nature. In order to maximize selffulfilment and social approval, one has to negotiate with the environment to locate the most acceptable solutions and option. Consequently, career choice and development is not a linear process of self-concept implementation, but a process of negotiations and compromises in which both the self and one's environment have to be consulted. The concept of life role can also be useful in understanding the cultural dynamics involved the career choice process. Values such filial piety, family harmony, and loyalty might influence how the personal selfis constructed, and the salience and importance of different life and work roles as well as their dynamic interactions. The contextual emphasis of Super's (1990) theory is most clearly depicted through his postulation of life roles and life space. Life at any moment is an aggregate of roles that one is assuming, such as child, student, leisurite, citizen, worker, parent, and homemaker. The salience of different life roles changes as one progress through life stages, yet at each single moment, two or three roles might take a more central place, while other roles remain on the peripheral. Life space is the constellation of different life roles that one is playing at a given time in different contexts or cultural "theatres", including home, community, school, and workplace. Role conflicts, role interference, and role confusions would likely happen when individuals are constrained in their ability to cope with the demands associated with their multiple roles.

Many aspects of Super's theory are attractive to international career guidance professional and researchers, including concepts such as vocational developmental tasks, developmental stages, career maturity and life roles. It offers a comprehensive framework to describe and explain the process of vocational development that could guide career interventions and research. The recent anchoring of the theory on developmental contextualism takes into consideration the reciprocal influence between the person and his/her social ecology, including one's culture. Likewise, the conceptualization of career choice and development as a process of personal and career construction recognizes the effects of subjective cultural values and beliefs in shaping vocational self-concepts and preferences. Even though international research on Super's theory is still very much needed, Super's theory will continue to play an important role in career development practice internationally.

3. Parson's Trait Theory of Career Development: Frank Parson is often credited as the founding father of modern career and vocational psychology. Parsons' (1909) process of studying individuals, considering occupations and matching them provided the foundation for trait and factor theory. Emanating out of the logical positivist worldview, trait and factor theory relies on measurement and objective data that is interpreted by an expert who, on that basis, also makes predictions about an individual's suitability for future jobs. The three main elements of his career development theory which helps in career selection are 


\section{Theories of Career Development: Educational and Counseling Implications}

a. A clear understanding of yourself, aptitudes, abilities, interests, resources, limitations and other qualities

b. A knowledge of the requirements and conditions of success, advantages and disadvantages, compensation, opportunities and prospects in different lines of work and

c. True reasoning on the relations of these two groups of facts

Each of these three elements represents a major contribution to career theory and practice, both of which formed a seamless amalgam to Parsons a point which in itself is significant given debate on the links between theory and practice. His first element is very important in his theory and is consistent with the contemporary approaches in career assessment and choices. Parsons acknowledged that individuals differ in terms of their interests, abilities, values, personality and skills. Parsons suggested that career counseling interview process would take fifteen minutes, a length of time which by today's counseling standards seems remarkably short. He also developed the first self-assessment form where clients completed a comprehensive questionnaire comprising over 100 questions prior to their career counseling interview. His assessment and interview process "established the format for career counseling. Thus, while Parsons introduced the concept of career assessment, it was not until the development of the psychometrics movement that the instruments needed to efficiently enhance self-knowledge and provide links to the world of work were provided. Parsons' second element relates to knowledge about the world of work, a concept he viewed as vital to comprehensive career planning and development and that has always been viewed as critical in career development work. Parallels can be drawn between the information sources advocated for use by Parsons with those used by modern day career counselors, including lists and classifications of industries, information on training and courses, and general industry information. The development of career information delivery systems so essential to modern career guidance also has its origins in the work of Parsons. Parsons' concept of 'true reasoning' remains to the present day his "most enduring contribution" to the field. It seems that he saw cognitive processes and analytical skills as fundamental to true reasoning and career selection. This reflects the visionary nature of his work and again emphasizes its relevance to modern career and guidance. Parson gave lots of importance to the role of intrapersonal and interpersonal factors in career decision making.

4. Gottfredson's Career Choice Theory of Circumscription and Compromise It is a recently develop theory of career development. Gottfredson (2005) assumed that career choice is a process requiring a high level of cognitive proficiency. A child's ability to synthesize and organize complex occupational information is a function of chronological age progression as well as general intelligence. Cognitive growth and development is instrumental to the development of a cognitive map of occupation and conceptions of self that are used to evaluate the appropriateness of various occupational alternatives. In contrast to the established notion that choice is a process of selection, Gottfredson's (2005) theorized that career choice and development could instead be viewed as a process of elimination or circumscription in which a

(C) The International Journal of Indian Psychology, ISSN 2348-5396 (e)| ISSN: 2349-3429 (p) | 220 


\section{Theories of Career Development: Educational and Counseling Implications}

person progressively eliminates certain occupational alternatives from further consideration. Circumscription is guided by salient aspects of self-concept emerging at different developmental stages. Gottfredson maintained that the career aspirations of children are influenced more by the public (e.g., gender, social class) than private aspects of their self-concept (e.g., skills, interests). A developmental model was proposed consisting of four stages of circumscription. The first is called "orientation to size and power" (ages 3-5), and the child perceives occupations as roles taken up by big people (adults). The second stage is called "orientation to s ex-roles"(ages 6-8), and in this stage sex-role norms and attitudes emerge as defining aspect of a child's self-concept. The child evaluates occupations according to whether they are appropriate to one's sex, and eliminates from further consideration alternatives that are perceived to be gender inappropriate (i.e., the wrong sex-type). The third stage is called "orientation to social valuation" (ages 9-13) as social class and status become salient to a child's developing self-concept. Accordingly, the emerging adolescent eliminates from further consideration occupations that are too low (i.e., occupations with unacceptable prestige levels) or too high (i.e., high prestige occupations beyond one's efficacy level) in prestige. The fourth stage is called "orientation to the internal, unique self" (ages 14 and above), in which internal and private aspects of the adolescent's self-concept, such as personality, interests, skills, and values, become prominent. The young adolescent considers occupations from the remaining pool of acceptable occupations according to their suitability or degree of match with one's internal self. Another career development process is compromise. In response to external realities and constraints such as changes in the structure of the economic depression, unfair hiring practices, and family obligations, individuals have to accommodate their occupational preferences so that their eventual choices are achievable in the real world. Compromise is a complex process in which compatibility with one's interest is often compromised first so as to maintain a greater degree of correspondence with one's preference for prestige and sex-type. Gottfredson's theory offers unique perspectives to career guidance professionals internationally. For instance, in many cultures life accomplishment is measured by successes in education and public examinations and attainment in career positions that have high social status and influence. Likewise, gender stereotype is also a part of many cultures (e.g., Asian cultures), and individuals are encouraged to pursue occupations that are perceived to be compatible to their gender. Hence, Gottfredson's theory offers a framework in which the influence of prestige and sex-type could be understood in diverse cultural contexts. Meanwhile, as career guidance interventions are becoming more central in primary and secondary schools around the world (Gysbers, 2000), the theory by Gottfredson could be used as a conceptual guide to program development. Gottfredson (2005) outlined a model of career guidance interventions aiming to reduce risk and enhance development, encouraging positive adaptation in relation to cognitive growth, self-creation, circumscription, and compromise. The model consisted of counsellor strategies and tools that could be used to optimize (a) learning and the use of complex occupational information, (b) experience and activities that allow children and adolescents to understand their career-related personal traits, (c) self-insight to construct and conceptualise a future career path that is realistic and feasible, and (d) wisdom in self-investment to elevate the 
odds of successfully implementing preferred career options. These broad strategies are applicable to a variety of cultural contexts in which opportunities exist for career interventions in school settings.

\section{Indigenisation of Career Theories}

Most of the career development theories have developed in the Western and more so in the USA and have served to guide career guidance practice and research internationally. They are still conceptually and empirically anchored in the social and occupational contexts of the USA, and career guidance practitioners and researchers should be careful not to transport these theories to their own contexts without cultural adaptation and modifications. A review of the conceptual literature in career development suggested that very few career development theories have emerged from regions outside the USA. In order to advance the career guidance discipline worldwide, there should be more "indigenous" efforts to develop theories and practice that would meet the idiosyncratic needs in diverse geographic regions. Indigenisation of career and guidance theory and practice should aim to identify the universals as well as the unique experience, constructs and practice that are specific to particular culture groups. The conceptualization on indigenisation by Enriquez (1993) could be used to guide the indigenisation of career development theories. Indigenisation of the career guidance discipline could take the route of indigenisation from within and indigenisation from without. There are three valid points and steps that need to be remembered in the context of indigenization of career development theories. These steps can be identified that should be taken to indigenise career development theories from without. These are

- First, international scholars in career guidance should examine how culture might intervene, moderate, or mediate the hypothesized career development and choice process.

- $\quad$ Second, career guidance scholars should develop instruments and measures that are reliable and valid for diverse cultures and

- $\quad$ The third step to indigenise career theories from within is the development of theory-based career guidance interventions in cross-cultural settings, incorporating cultural adaptations that are based on local social, cultural, and occupational features.

\section{SUMMARY AND CONCLUSION}

A number of career development theories have been proposed. Each theory stresses one point of view and thus does not explain the complex process in its totality. For the professional career counselors, the various theories of career development provide useful points of departure. Since the clients come from different cultural backgrounds and hold different views, no single theory can satisfactorily explain the complex process of career and vocational choice. There is a strong need to formulate indigenous theories to have cross cultural validity which in turn will help in developing culture fair vocational and career selection psychological tests. In India, career choices are often parents' choice based and not individual choice based, there is a need to sensitize the teachers and the parents about the importance of individual's interest based career

(C) The International Journal of Indian Psychology, ISSN 2348-5396 (e)| ISSN: 2349-3429 (p) | 222 
decision making which will not only give a feeling of contentment and mastery, in long run it might help improving social and economic capital of the country.

\section{Acknowledgement}

I am grateful to Mr. Mustafa Nadeem Kirmani, NIMHANS trained clinical psychologist in helping and guiding me in preparing this paper.

\section{REFERENCES}

Athanasou, J.A., \& R. Van Esbroeck (2008).International Handbook of Career Guidance, 115 (C) Springer Science + Business Media B.V.

Edbroeck, R. V., \& Vianen, A. E. M. (2009). Life designing: A paradigm for career construction in the 21st century. Journal of Vocational Behavior, 75(3), 239-250.

Enriquez, V. G. (1993). Developing a Filipino psychology. In U. Kim \& J. W. Berry (Eds.), Indigenous psychologies: Research and experience in cultural context (pp. 152-169). Newbury Park, CA: Sage.

Gladding, S. T. (1992). Counseling a Comprehensive Profession (3rd Edition). Eaglewood Cliffs: Prentice Hall, Inc

Gottfredson, L. S. (1981). Circumscription and compromise: A developmental theory of occupational aspirations [Monograph]. Journal of Counseling Psychology, 28, 545-579.

Gottfredson, L. S. (2002). Gottfredson's theory of circumscription, compromise, and selfcreation. In D. Brown \& Associate (Eds.), Career choice and development (4th ed., pp. 85-148). San Francisco, CA: Jossey-Bass

Gottfredson, L. S. (2005). Applying Gottfredson's theory of circumscription and compromise in career guidance and counseling. In S. D. Brown \& R. T. Lent (Eds.), Career development and counseling: Putting theory and research to work (pp. 71-100). Hoboken, NJ: Wiley.

Gysbers, N. C. (2000). Implementing a whole school approach to guidance through a comprehen- sive guidance system. Asian Journal of Counseling, 7, 5-17.

Patton,W.,\&McMahon, M.(2014).Career Development and Systems Theory Connecting Theory and Practice ( $3^{\text {rd }}$ ed). Sense Publishers: Boston

Savickas, M. \& Lent, R. (1994). Convergence in Career Development Theories. Palo Alto, California:

Super, D. E. (1957).The psychology of careers: An introduction to vocational development. New York: Harper \& Row.

Weinert, A. B. (2001). Psychology of career development. International Encyclopaedia of the Social \& Behavioral Sciences, Elsevier Science, 1471-147

Zunker, V. G. (2006). Career Counseling: A holistic approach. Belmont, C.A: Thomson Books/Cole

How to cite this article: P Sharma (2016), Theories of Career Development: Educational and Counseling Implications, International Journal of Indian Psychology, Volume 3, Issue 4, No. 63, ISSN 2348-5396 (e), ISSN: 2349-3429 (p), DIP: 18.01.116/20160304, ISBN: 978-1-365-325182

(c) The International Journal of Indian Psychology, ISSN 2348-5396 (e)| ISSN: 2349-3429 (p) | 223 